\title{
Sarcoplasmic Reticulum-associated Cyclic Adenosine 5'-Monophosphate Phosphodiesterase Activity in Normal and Failing Human Hearts
}

\author{
Matthew A. Movsesian, * Carolyn J. Smith, ${ }^{\star}$ Judith Krall,“ Michael R. Bristow, ${ }^{\star}$ and Vincent C. Manganiello \\ ${ }^{*}$ Cardiology Division, University of Utah Medical Center, Salt Lake City, Utah 84132; and ${ }^{\ddagger}$ Laboratory of Cellular Metabolism, \\ National Heart, Lung, and Blood Institute, National Institutes of Health, Bethesda, Maryland 20814
}

\begin{abstract}
Sarcoplasmic reticulum-associated cAMP phosphodiesterase activity was examined in microsomes prepared from the left ventricular myocardium of eight heart transplant recipients with end-stage idiopathic dilated cardiomyopathy and six unmatched organ donors with normal cardiac function. At cAMP concentrations $\leq 1.0 \mu \mathrm{M}$, sarcoplasmic reticulum-associated cAMP phosphodiesterase activity was functionally homogeneous. cAMP phosphodiesterase activity was inhibited competitively by cGMP $\left(K_{\mathrm{i}}=0.031 \pm 0.008 \mu \mathrm{M}\right)$ and the cilostamide derivative OPC $3911\left(K_{\mathrm{i}}=0.018 \pm 0.004 \mu \mathrm{M}\right)$, but was essentially insensitive to rolipram. $V_{\max }$ and $K_{\mathrm{m}}$ were $781.7 \pm 109.2$ $\mathrm{nmol} / \mathrm{mg}$ per $\mathrm{min}$ and $0.188 \pm 0.031 \mu \mathrm{M}$, respectively, in microsomes prepared from nonfailing hearts and $793.9 \pm 68.9 \mathrm{nmol} /$ mg per min and $0.150 \pm 0.027 \mu \mathrm{M}$ in microsomes prepared from failing hearts. Microsomes prepared from nonfailing and failing hearts did not differ with respect to either the ratio of cAMP phosphodiesterase activity to ATP-dependent $\mathrm{Ca}^{2+}$ accumulation activity or the sensitivity of cAMP phosphodiesterase activity to inhibition by OPC 3911 . These data suggest that the diminished inotropic efficacy of phosphodiesterase inhibitors in failing human hearts does not result from changes in the level, kinetic properties, or pharmacologic sensitivity of sarcoplasmic reticulum-associated cAMP phosphodiesterase activity. (J. Clin. Invest. 1991. 88:15-19.) Key words: phosphodiesterase inhibitors $\bullet$ cyclic guanosine 5'-monophosphate • cilostamide $\cdot$ rolipram $\cdot \mathrm{Ca}^{2+}$ transport
\end{abstract}

\section{Introduction}

Certain drugs that inhibit cAMP hydrolysis by cyclic nucleotide phosphodiesterases increase myocardial contractility, and there is interest in the potential usefulness of such agents in the treatment of heart failure. Five distinct families of cyclic nucleotide phosphodiesterases have been identified and characterized (1). Studies in animals suggest that the inotropic efficacy of phosphodiesterase inhibitors is most closely related to their ability to inhibit the activity of enzymes belonging to the cGMP-inhibited cAMP phosphodiesterase family (cGI PDE ${ }^{1}$,

Address correspondence to Dr. Matthew A. Movsesian, Cardiology Division, Room 4A-100, University of Utah Health Sciences Center, 50 North Medical Drive, Salt Lake City, UT 84132.

Received for publication 25 October 1990 and in revised form 16 January 1991.

1. Abbreviation used in this paper: cGI-PDE, cGMP-inhibited cAMP phosphodiesterase.

The Journal of Clinical Investigation, Inc.

Volume 88, July 1991, 15-19 often referred to as PDE III), which are characterized by their high affinity for cAMP, insensitivity to rolipram, and susceptibility to competitive inhibition by low concentrations of cGMP, cilostamide derivatives, and some of the newer inotropic agents such as milrinone, amrinone, and enoximone (2-8). In addition, the association of CGI PDE with the sarcoplasmic reticulum appears to be an important determinant of the inotropic efficacy of these agents. In dog and rhesus monkey, whose cGI PDE activity is localized to the sarcoplasmic reticulum, cGI PDE inhibitors are very effective as inotropic agents. These inhibitors are much less effective inotropic agents in hamster, guinea pig, and rat, whose cGI PDE activity is predominantly cytoplasmic $(9,10)$.

Studies of tension development in muscle strips obtained from normal and failing human hearts have demonstrated a decreased inotropic response to phosphodiesterase inhibitors in the latter $(11,12)$. As suggested in these reports, this diminished augmentation of tension development may reflect impaired cAMPgeneration. It is also plausible, however, that alterations in sarcoplasmic reticulum-associated cGI PDE activity contributed to the diminished response. To investigate this possibility, we examined and compared the characteristics of sarcoplasmic reticulum-associated cAMP phosphodiesterase activity in microsomes prepared from normal and failing human hearts.

\section{Methods}

Procurement of human cardiac tissue. Left ventricular free wall myocardium was obtained from the excised failing hearts of eight transplant recipients (age $49.1 \pm 5.4 \mathrm{yr}$ ) with class IV heart failure resulting from idiopathic dilated cardiomyopathy, and the nonfailing hearts of six unmatched organ donors (age $40.3 \pm 6.7 \mathrm{yr}$ ). The sarcolemmal $\beta$-adrenergic receptor density, measured as previously described $(13,14)$, was $99.8 \pm 14.4 \mathrm{fmol} / \mathrm{mg}$ in the nonfailing hearts and $49.8 \pm 5.0 \mathrm{fmol} / \mathrm{mg}$ in the failing hearts $(P<0.01)$.

Preparation of human cardiac microsomes. Microsomes were prepared from left ventricular free wall myocardial tissue as previously described (15), save that the $\mathrm{pH}$ of the buffer solutions used in the homogenization and differential sedimentation steps was adjusted to 6.0 rather than 7.0. This modification increased the specific cAMP phosphodiesterase activity without decreasing total cAMP phosphodiesterase activity.

Measurement of CAMP phosphodiesterase activity. The method for measuring CAMP phosphodiesterase activity was adapted from the protocol described by Kincaid and Manganiello (16). Unless otherwise stated, microsomes were suspended at $0.012 \mathrm{mg} / \mathrm{ml}$ in a reaction mixture comprised of $0.1 \mathrm{mM}$ EGTA, $8.3 \mathrm{mM} \mathrm{MgCl}_{2}$, and $50 \mathrm{mM}$ Hepes $\left(\mathrm{pH} 7.5,30^{\circ} \mathrm{C}\right)$. cAMP hydrolysis was initiated by addition of $\left[{ }^{3} \mathrm{H}\right]$ cAMP (New England Nuclear, Boston, MA); each assay was performed in duplicate. The reaction was stopped by the addition of $10.1 \mathrm{mM}$ unlabelled cAMP and $5 \mathrm{mM}$ unlabelled 5'AMP in $0.25 \mathrm{~N} \mathrm{HCl}$. The reaction mixture was neutralized with $\mathrm{NaOH}$, and $\left[{ }^{3} \mathrm{H}\right] 5^{\prime} \mathrm{AMP}$ was converted to $\left[{ }^{3} \mathrm{H}\right]$ adenosine by incubation with Crotalus atrox venom 
$(30 \mathrm{mg} / \mathrm{ml})$ at $30^{\circ} \mathrm{C}$ for $30 \mathrm{~min}$. The reaction mixture was then applied to QAE-Sephadex columns, and adenosine was eluted with $\mathrm{H}_{2} \mathrm{O}$ at neutral $\mathrm{pH}$. cAMP hydrolysis was determined by measuring $\left[{ }^{3} \mathrm{H}\right]-$ adenosine in the eluent by scintillation spectrometry. Values for $V_{\max }$, $K_{\mathrm{m}}$, and $K_{\mathrm{i}}$ were determined by weighted nonlinear least squares regression analysis (Gauss-Newton method) using published computer programs (17).

Microsomal cAMP phosphodiesterase activity was also measured using the same technique in buffer comprised of $0.102 \mathrm{mM} \mathrm{KCl}, 5.24$ $\mathrm{mM} \mathrm{MgCl}, 1.00 \mathrm{mM}$ EGTA, $0.40 \mathrm{mM} \mathrm{CaCl}_{2}, 5 \mathrm{mM} \mathrm{ATP}$, and 20 $\mathrm{mM}$ [ $N$-morpholino]propanesulfonic acid (MOPS) $\left(\mathrm{pH} 7.05,37^{\circ} \mathrm{C}\right.$ ). The free $\mathrm{Mg}^{2+}$ concentration was calculated to be $0.8 \mathrm{mM}$ and the free $\mathrm{Ca}^{2+}$ concentration was calculated to be $0.2 \mu \mathrm{M}$ (18).

Miscellaneous. Protein was measured according to the method of Bradford using bovine serum albumin as a standard (19). Lipids were extracted from microsomes by the method of Bligh and Dyer (20), and the phosphorus contents of the extracts were quantified by the method of Chen et al. (21). Oxalate-supported, ATP-dependent $\mathrm{Ca}^{2+}$ accumulation by human cardiac microsomes was measured as previously described (15) in the presence of $0.102 \mathrm{M} \mathrm{KCl}, 5.05 \mathrm{mM} \mathrm{MgCl}_{2}, 1.0 \mathrm{mM}$ EGTA, $0.99 \mathrm{mM} \mathrm{CaCl}_{2}, 5.0 \mathrm{mM}$ oxalic acid, $5.0 \mathrm{mM} \mathrm{NaN}_{3}, 0.5 \mathrm{mM}$ ryanodine, $5.0 \mathrm{mM}$ ATP, and $20 \mathrm{mM}$ MOPS $\left(\mathrm{pH}=7.05,37^{\circ} \mathrm{C}\right)$. The free $\mathrm{Ca}^{2+}$ concentration was calculated to be $5.0 \mu \mathrm{M}$ (18). OPC 3911 was supplied by Otsuka Chemicals, Ltd., Osaka, Japan.

\section{Results}

Sarcoplasmic reticulum-associated cAMP phosphodiesterase activity was measured under standard conditions in microsomes prepared from left ventricular free wall myocardium obtained from failing human hearts. In Fig. 1, cAMP phosphodiesterase activity is plotted as a function of cAMP concentration in double reciprocal form. The linearity of the double reciprocal plot indicates that the cAMP phosphodiesterase activity associated with the sarcoplasmic reticulum follows the Michaelis-Menton steady-state model, with $V_{\max }=533 \pm 18$ $\mathrm{pmol} / \mathrm{mg}$-min and $K_{\mathrm{m}}=0.133 \pm 0.013 \mu \mathrm{M}$ in this preparation.

The high affinity for cAMP suggested that the CAMP phosphodiesterase activity associated with human cardiac sarcoplasmic reticulum reflected the presence of either cGMP- or rolipram-inhibited phosphodiesterases. To distinguish between these possibilities, the effects of specific inhibitors of these phosphodiesterase families were examined (Fig. 2). At 0.2 $\mu \mathrm{M}$ cAMP, cAMP hydrolysis was potently inhibited by cGMP $\left(\mathrm{IC}_{50}=0.098 \mu \mathrm{M}\right)$ and the water-soluble cilostamide derivative OPC $3911\left(\mathrm{IC}_{50}=0.048 \mu \mathrm{M}\right)$. In contrast, inhibition by roli-

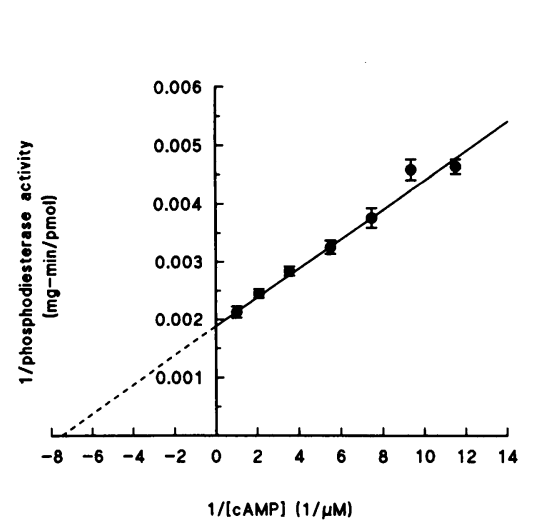

Figure 1. cAMP phosphodiesterase activity in human cardiac sarcoplasmic reticulum. Measurements were made in a single preparation using tissue combined from three explanted failing hearts. Data are plotted in double reciprocal form. Each point represents the mean \pm standard error of six to eight determinations.

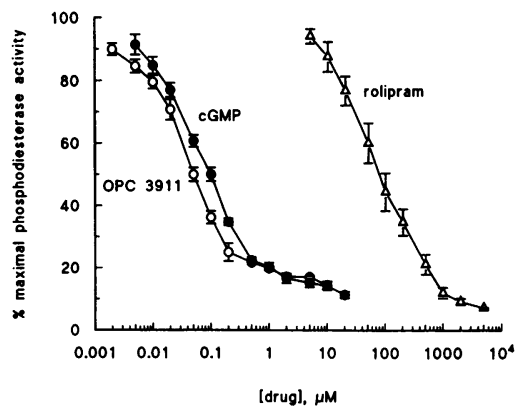

Figure 2. Inhibition of cAMP phosphodiesterase activity by OPC 3911 (open circles), cGMP ( filled circles), and rolipram (open triangles). Measurements were made at $0.2 \mu \mathrm{M}$ cAMP. The sarcoplasmic reticulum preparation was the same as that used in Fig. 1. Each point represents the mean \pm standard error of four to six determinations.

pram was observed only at very high concentrations of the drug $\left(\mathrm{IC}_{50}=76.9 \mu \mathrm{M}\right)$. When inhibition of cAMP phosphodiesterase activity by cGMP and OPC 3911 was examined as a function of cAMP concentration, it was seen to be competitive, with $K_{\mathrm{i}}$ values of $0.031 \pm 0.008 \mu \mathrm{M}$ for CGMP and $0.018 \pm 0.004$ $\mu \mathrm{M}$ for OPC 3911 (Fig. 3). This pattern of inhibition is typical of CGI PDE.

These observations demonstrated the feasibility of determining values for the steady-state kinetic parameters of sarcoplasmic reticulum-associated cAMP phosphodiesterase in microsomes prepared from normal and failing human hearts. Before comparing these values, however, it was necessary to demonstrate that our preparative methods resulted in the isolation of comparable microsomal fractions in the two populations. As shown in Table I, microsomes prepared from normal and failing hearts were similar with respect to yield and phospholipid:protein ratio (expressed as nanomoles of extractable phosphorus per milligram protein). In addition, oxalate-supported, ATP-dependent $\mathrm{Ca}^{2+}$ accumulation activity was assayed as an index of sarcoplasmic reticulum function. As in
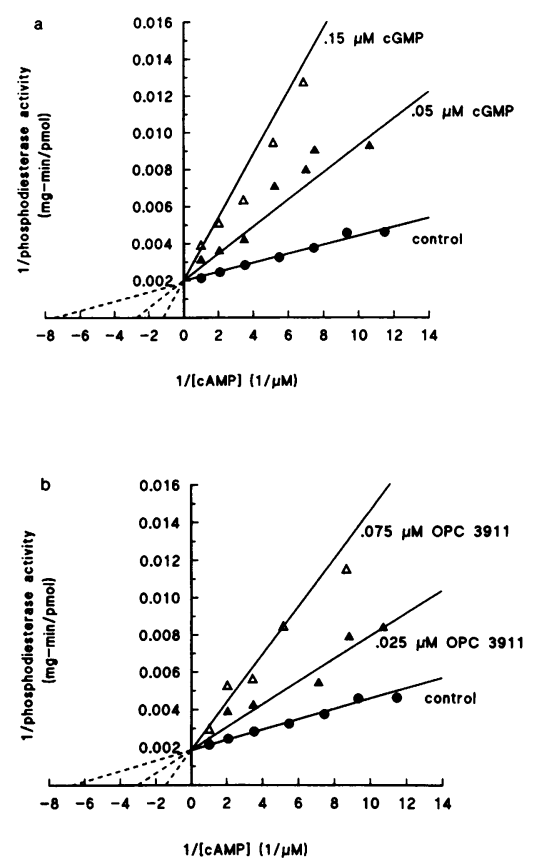

Figure 3. Inhibition of cAMP phosphodiesterase activity by CGMP and OPC 3911. cAMP phosphodiesterase activity was measured in the absence ( filled circles) and presence of $0.05 \mu \mathrm{M}$ (filled triangles) and $0.15 \mu \mathrm{M}$ (open triangles) cGMP (a), and in the absence ( filled circles) and presence of $0.025 \mu \mathrm{M}$ ( filled triangles) and $0.075 \mu \mathrm{M}$ (open triangles) OPC 3911 (b). Data are plotted in double reciprocal form. The sarcoplasmic reticulum preparation was the same as that used in Fig. 1. Each point represents the mean of four to eight determinations. 
Table I. Characteristics of Microsomes Prepared from Normal and Failing Hearts

\begin{tabular}{lccc}
\hline & Yield & Phospholipid/protein & $\mathrm{Ca}^{2+}$ accumulation \\
\hline & $m g / g$ & $n m o l / m g$ & $n$ mol/mg per min \\
Normal $(n=6)$ & $0.42 \pm 0.07$ & $36.9 \pm 4.5$ & $478.3 \pm 78.7$ \\
Failing $(n=8)$ & $0.38 \pm 0.05$ & $33.0 \pm 3.5$ & $514.2 \pm 41.0$
\end{tabular}

Assays were performed as described. Each value is the mean \pm standard error.

previous studies $(15,22)$, this activity was similar in preparations from normal and failing hearts.

These findings confirmed that microsomes prepared from normal and failing hearts were comparable with respect to sarcoplasmic reticulum content and activity. Values for $V_{\max }$ and $K_{\mathrm{m}}$ for cAMP phosphodiesterase activity in these preparations are listed in Table II. No differences between preparations from normal and failing hearts were observed with respect to either parameter. In addition, the ratio of cAMP phosphodiesterase activity to $\mathrm{Ca}^{2+}$ accumulation activity was determined in each preparation. The preparations from normal and failing hearts did not differ with respect to this ratio.

It remained possible that physiologically significant differences between normal and failing hearts with respect to sarcoplasmic reticulum-associated cAMP phosphodiesterase activity were present but were not detected under the chosen assay conditions. For this reason, sarcoplasmic reticulum-associated cAMP phosphodiesterase activity in microsomes prepared from normal and failing hearts was reexamined under conditions selected to more closely resemble the intracellular environment. Specifically, cAMP phosphodiesterase activity was assayed in the presence of $105 \mathrm{mM} \mathrm{KCl}, 0.8 \mathrm{mM} \mathrm{Mg}^{2+}, 0.2 \mu \mathrm{M}$ $\mathrm{Ca}^{2+}$, and $5 \mathrm{mM}$ ATP at $\mathrm{pH} 7.05\left(37^{\circ} \mathrm{C}\right)$. The free $\mathrm{Ca}^{2+}$ concentration in cardiac myocytes varies throughout the cardiac cycle; the value of $0.2 \mu \mathrm{M}$ was chosen because the most well-characterized local substrate for CAMP-dependent protein kinase is phospholamban, and the effects of phospholamban phosphorylation on $\mathrm{Ca}^{2+}$ accumulation by human cardiac sarcoplasmic

Table II. Steady-state Kinetic Parameters of Sarcoplasmic Reticulum-associated cAMP Phosphodiesterase Activity in Microsomes Prepared from Normal and Failing Hearts

\begin{tabular}{lccc}
\hline & \multicolumn{2}{c}{ cAMP phosphodiesterase activity } & $\begin{array}{c}\text { Ratio of } \\
\text { phosphodiesterase } \\
\text { activity/Ca }{ }^{2+} \\
\text { accumulation }\end{array}$ \\
\cline { 2 - 3 } & $V_{\max }$ & $K_{\mathrm{m}}$ & $\times 10^{3}$ \\
& pmol/mg per min & $\mu M$ & $1.75 \pm 0.30$ \\
Normal $(n=6)$ & $781.7 \pm 109.2$ & $0.188 \pm 0.031$ & $1.55 \pm 0.07$ \\
Failing $(n=8)$ & $793.9 \pm 68.9$ & $0.150 \pm 0.027$ & \\
\hline
\end{tabular}

Assays were performed as described. Values in the third column were obtained by dividing $V_{\max }$ for cAMP phosphodiesterase activity by the rate of ATP-dependent, oxalate-supported $\mathrm{Ca}^{2+}$ accumulation (measured at $5.0 \mu \mathrm{M} \mathrm{Ca}^{2+}$ ) in each preparation. Each value is the mean \pm standard error. reticulum are most pronounced at this $\mathrm{Ca}^{2+}$ concentration (22). The value of $0.8 \mathrm{mM}$ for the free $\mathrm{Mg}^{2+}$ concentration was chosen on the basis of nuclear magnetic resonance estimates of intracellular $\mathrm{Mg}^{2+}$ concentrations (23). Under these conditions, cAMP phosphodiesterase activity was $202.2 \pm 11.0 \mathrm{pmol} /$ $\mathrm{mg}$ per $\mathrm{min}$ in the preparations from normal hearts and $196.4 \pm 25.7 \mathrm{pmol} / \mathrm{mg}$ per min in the preparations from failing hearts. These values are essentially identical.

Finally, to compare the sensitivity of sarcoplasmic reticulum-associated cAMP phosphodiesterase activity in normal and failing hearts to pharmacologic inhibition, cAMP phosphodiesterase activity in microsomal preparations was examined at $0.2 \mu \mathrm{M}$ cAMP in the absence and presence of $0.05 \mu \mathrm{M}$ OPC 3911. As shown in Table III, no difference between the two groups was apparent.

\section{Discussion}

The steady-state kinetic parameters of cAMP hydrolysis in cardiac microsomes and its sensitivity to inhibition by cGMP and OPC 3911 suggest that the cAMP phosphodiesterase activity associated with human left ventricular sarcoplasmic reticulum belongs to the cGI PDE family. The linearity of the double reciprocal plots and the relative insensitivity to inhibition by rolipram suggest additionally that the activity is functionally homogeneous, and that CGI PDE is the predominant (if not sole) species responsible for cAMP hydrolysis at submicromolar concentrations of CAMP in human cardiac sarcoplasmic reticulum. Similar findings have been reported in rabbit and canine preparations $(7,9)$. The values for $K_{\mathrm{m}}$ for cAMP and $K_{\mathrm{i}}$ for inhibition of cAMP phosphodiesterase activity by cGMP in our preparations are similar to values reported for highly purified bovine cardiac $\left(K_{\mathrm{m}}=0.15 \mu \mathrm{M}, K_{\mathrm{i}}=0.06 \mu \mathrm{M}\right.$, reference 6) and human platelet $\left(K_{\mathrm{m}}=0.18 \mu \mathrm{M}, K_{\mathrm{i}}=0.035 \mu \mathrm{M}\right.$, reference 24) forms of cGI PDE, as well to those reported for less highly purified preparations of the human cardiac enzyme $\left(K_{\mathrm{m}}=0.14\right.$ $\mu \mathrm{M}$ in reference 25 and $0.36 \mu \mathrm{M}$ in reference 26 ).

Our comparison of sarcoplasmic reticulum-associated cGI PDE activity in microsomes prepared from normal and failing human hearts revealed no significant differences with respect

Table III. Inhibition of Sarcoplasmic Reticulum-associated cAMP Phosphodiesterase Activity in Microsomes Prepared from Normal and Failing Hearts

\begin{tabular}{|c|c|c|c|}
\hline & \multicolumn{2}{|c|}{ Phosphodiesterase activity } & \multirow[b]{2}{*}{$\begin{array}{c}\text { Percent } \\
\text { inhibition }\end{array}$} \\
\hline & Control & $\begin{array}{l}\text { OPC } 3911 \\
(0.05 \mu \mathrm{M})\end{array}$ & \\
\hline & \multicolumn{2}{|c|}{ pmol/mg per min } & \\
\hline Normal $(n=6)$ & $402.8 \pm 49.9$ & $175.2 \pm 25.3$ & $56.6 \pm 3.0$ \\
\hline Failing $(n=8)$ & $415.2 \pm 38.6$ & $175.3 \pm 15.7$ & $57.4 \pm 1.4$ \\
\hline
\end{tabular}

cAMP phosphodiesterase activity was measured at $0.2 \mu \mathrm{M}$ cAMP in the absence or presence of $0.05 \mu \mathrm{M}$ OPC 3911. Each value is the mean \pm standard error. 
to $V_{\max }$ and $K_{\mathrm{m}}$ for cAMP or the ratio of cGI PDE activity to ATP-dependent $\mathrm{Ca}^{2+}$ transport. Furthermore, we found no difference between the two groups with respect to susceptibility of sarcoplasmic reticulum-associated cGI PDE activity to inhibition by OPC 3911 . Based on these results, the decreased inotropic efficacy of phosphodiesterase inhibitors in tissue from failing human hearts cannot be ascribed to intrinsic alterations in sarcoplasmic-reticulum associated cGI PDE activity.

It remains possible that normal and failing hearts differ with respect to the regulation of phosphodiesterase activity. In intact cell preparations, human platelet and rat adipocyte cGI PDE's are phosphorylated and activated by agents that increase intracellular cAMP concentrations, and phosphorylation of the human platelet enzyme by cAMP-dependent protein kinase in vitro results in stimulation of cAMP phosphodiesterase activity $(27,28)$. To date, stimulation of phosphodiesterase activity by phosphorylation has not been observed in cardiac preparations, but further study of this issue seems warranted. In addition, the low $K_{\mathrm{i}}$ for inhibition of cAMP phosphodiesterase activity by cGMP raises the possibility that cGMP is involved in the regulation of the enzyme in vivo. The competitive nature of this inhibition suggests that this regulation may be particularly significant in failing human myocardium, where intracellular cAMP concentrations may be low due to $\beta_{1}$ receptor downregulation and partial uncoupling of $\beta_{2}$ receptors from adenylate cyclase $(13,29)$.

It is also possible that sarcoplasmic reticulum structure is altered in failing human myocardium. As noted earlier, studies in animals suggest that the inotropic efficacy of phosphodiesterase inhibitors may depend upon the association of the enzyme with the sarcoplasmic reticulum. cAMP metabolism in cardiac myocytes appears to be compartmentalized (30), and the association of CGI PDE with the sarcoplasmic reticulum may provide a mechanism for the local regulation of CAMP-dependent protein kinase activation and the selective phosphorylation of phospholamban. This phosphorylation results in stimulation of $\mathrm{Ca}^{2+}$ accumulation by human cardiac sarcoplasmic reticulum in vitro (22), and myocardial contraction and relaxation may be modulated via the effects of this stimulation on intracellular $\left[\mathrm{Ca}^{2+}\right]$ transients. Alterations affecting the proximity of cGI PDE to phospholamban in failing myocardium could result in dissociation of phosphodiesterase inhibition from its effects on sarcoplasmic reticulum $\mathrm{Ca}^{2+}$ handling, and the diminished inotropic efficacy of phosphodiesterase inhibitors in failing myocardium might be explained on this basis.

Finally, the possibility that interactions with other intracellular pools of cGI PDE are involved in the inotropic effects of phosphodiesterase inhibitors in humans must be considered. The presence of cGI PDE activity in the cytoplasmic fractions of human myocardium has been reported (26), but whether this activity was present in the cytoplasm in vivo is unclear: the tissue used in the study referred to was obtained post-mortem, and the cGI PDE activity identified as 'cytoplasmic' may have been dissociated from the sarcoplasmic reticulum artifactually during the preparation (we were able to dissociate a significant fraction of cGI PDE activity from the sarcoplasmic reticulum in our preparations simply by freezing and thawing). Determining the intracellular distribution of CGI PDE in human myocardium in vivo using ultrastructural methods may be especially useful in this regard.

\section{Acknowledgments}

This work was supported in part by a grant from the American Heart Association (Utah Affiliate)

\section{References}

1. Beavo, J. A. 1988. Multiple isozymes of cyclic nucleotide phosphodiesterase. Adv. Second Messenger Phosphoprotein Res. 22:1-38.

2. Bethke, T., D. Brunkhorst, H. v. der Leyen, W. Meyer, R. Nigbur, and H. Scholz. 1988. Mechanism of action and cardiotonic activity of a new phosphodiesterase inhibitor, the benzimidazole derivative adibendan (BM 14.478), in guinea-pig hearts. Arch. Pharmacol. 337:576-582.

3. Brunkhorst, D., H. van der Leyen, W. Meyer, R. Nigbur, C. Schmidt-Schumacher, and H. Scholz. 1989. Relation of positive inotropic and chronotropic effects of pimobendan, UD-CG $212 \mathrm{Cl}$, milrinone and other phosphodiesterase inhibitors to phosphodiesterase III inhibition in guinea-pig heart. Arch. Pharmacol. 339:575-583.

4. Kariya, T., L. J. Wille, and R. C. Cage. 1982. Biochemical studies on the mechanism of cardiotonic activity of MDL 17,043. J. Cardiovasc. Pharmacol. 4:509-514.

5. Silver, P. J., A. L. Harris, P. C. Canniff, R. E. Lepore, R. G. Bentley, L. T. Hamel, and D. B. Evans. 1989. Phosphodiesterase isozyme inhibition, activation of the cAMP system, and positive inotropy mediated by milrinone in isolated guinea-pig cardiac muscle. J. Cardiovasc. Pharmacol. 13:530-540.

6. Harrison, S. A., D. H. Reifsnyder, B. Gallis, G. G. Cadd, and J. A. Beavo. 1986. Isolation and characterization of bovine cardiac muscle cGMP-inhibited phosphodiesterase: a receptor for new cardiotonic drugs. Mol. Pharmacol. 29:506-514.

7. Kithas, P. A., M. Artman, W. J. Thompson, and S. J. Strada. 1988. Subcellular distribution of high-affinity type IV cyclic AMP phosphodiesterase activity in rabbit ventricular myocardium: relations to the effects of cardiotonic drugs. Circ. Res. 62:782-789.

8. Kauffman, R. F., V. G. Crowe, B. G. Utterback, and D. W. Robertson. 1986. LY 195115: a potent, selective inhibitor of cyclic nucleotide phosphodiesterase located in the sarcoplasmic reticulum. Mol. Pharmacol. 30:609-616.

9. Weishaar, R. E., D. C. Kobylarz-Singer, R. P. Steffen, and H. R. Kaplan. 1987. Subclasses of cyclic AMP-specific phosphodiesterase in left ventricular muscle and their involvement in regulating myocardial contractility. Circ. Res. 61:539-547.

10. Weishaar, R. E., D. C. Kobylarz-Singer, M. M. Quade, R. P. Steffen, and H. R. Kaplan. 1987. Multiple molecular forms of phosphodiesterase and the regulation of cardiac muscle contractility. J. Cyclic Nucleotide Protein Phosphorylation Res. 11:513-527.

11. Bohm, M., F. Diet, G. Feiler, B. Kemkes, E. Kreuzer, C. Weinhold, and E. Erdmann. 1988. Subsensitivity of the failing human heart to isoprenaline and milrinone is related to $\beta$-adrenoceptor downregulation. J. Cardiovasc. Pharmacol. 12:726-732.

12. Feldman, M. D., L. Copelas, J. K. Gwathmey, P. Phillips, S. E. Warren, F. J. Schoen, W. Grossman, and J. P. Morgan. 1987. Deficient production of cyclic AMP: pharmacologic evidence of an important cause of contractile dysfunction in patients with end-stage heart failure. Circulation. 75:331-339.

13. Bristow, M. R., R. Ginsburg, V. Umans, M. Fowler, W. Minobe, R Rasmussen, P. Zera, R. Menlove, P. Shah, S. Jamieson, and E. B. Stinson. 1986 $\beta_{1}$-and $\beta_{2}$-adrenergic-receptor subpopulations in nonfailing and failing human ventricular myocardium: coupling of both receptor subtypes to muscle contraction and selective $\beta_{1}$-receptor down-regulation in heart failure. Circ. Res. 59:297309.

14. Bristow, M. R., R. Ginsburg, A. Strosberg, W. Montgomery, and W. Minobe. 1984. Pharmacology and inotropic potential of forskolin in the human heart. J. Clin. Invest. 74:212-223.

15. Movsesian, M. A., M. R. Bristow, and J. Krall. 1989. $\mathrm{Ca}^{2+}$ uptake by cardiac sarcoplasmic reticulum from patients with idiopathic dilated cardiomyopathy. Circ. Res. 65:1141-1144.

16. Kincaid, R. L., and V. C. Manganiello. 1988. Assay of cyclic nucleotide phosphodiesterase using radiolabeled and fluorescent substrates. Methods Enzymol. $159: 457-470$.

17. Cleland, W. W. 1979. Statistical analysis of enzyme kinetic data. Methods Enzymol. 63:103-138.

18. Fabiato, A. 1988. Computer programs for calculating total from specified free or free from specified total ionic concentrations in aqueous solutions containing multiple metals and ligands. Methods Enzymol. 157:378-417.

19. Bradford, M. M. 1976. A rapid and sensitive method for the quantitation of microgram quantities of protein utilizing the principle of protein-dye binding Anal. Biochem. 72:248-254. 
20. Bligh, E. G., and W. J. Dyer. 1959. A rapid method of total lipid extraction and purification. Can. J. Biochem. Physiol. 37:911-917.

21. Chen, P. S., Jr., T. Y. Toribara, and H. Warner. 1956. Microdetermination of phosphorus. Anal. Chem. 28:1756-1758.

22. Movsesian, M. A., J. Colyer, J. H. Wang, and J. Krall. 1990. Phospholamban-mediated stimulation of $\mathrm{Ca}^{2+}$ uptake in sarcoplasmic reticulum from normal and failing hearts. J. Clin. Invest. 85:1698-1702.

23. Gupta, R. K., and P. Gupta. 1987. ${ }^{31} \mathrm{P}$ measurement of intracellular free magnesium in cells and organelles. In NMR Spectroscopy of Cells and Organisms. Vol. II. R. K. Gupta, editor. CRC Press, Inc., Boca Raton, FL. 34-43.

24. Grant, P. G., and R. W. Colman. 1984. Purification and characterization of a human platelet cyclic nucleotide phosphodiesterase. Biochemistry. 23:18011807.

25. Reeves, M. L., B. K. Leigh, and P. J. England. 1987. The identification of a new cyclic nucleotide phosphodiesterase activity in human and guinea pig cardiac ventricle. Biochem. J. 241:535-541.
26. Masuoka, H., M. Ito, T. Nakano, M. Naka, and T. Tanaka. 1990. Effects of amrinone and enoximone on the subclasses of cyclic AMP phosphodiesterase from human heart and kidney. J. Cardiovasc. Pharmacol. 15:302-307.

27. Degerman, E., C. J. Smith, H. Tornqvist, V. Vasta, P. Belfrage, and V. C Manganiello. 1990. Evidence that insulin and isoprenaline activate the cGMP-inhibited low- $\mathrm{K}_{\mathrm{m}} \mathrm{cAMP}$ phosphodiesterase in rat fat cells by phosphorylation. Proc. Natl. Acad. Sci. USA. 87:533-537.

28. Macphee, C. H., D. H. Reifsnyder, T. A. Moore, K. M. Lerea, and J. A. Beavo. 1988. Phosphorylation results in activation of a cAMP phosphodiesterase in human platelets. J. Biol. Chem. 263:10353-10358.

29. Bristow, M. R., R. E. Hershberger, J. D. Port, W. Minobe, and R. Rasmussen. 1989. $\beta_{1}$ - and $\beta_{2}$-adrenergic receptor-mediated adenylate cyclase stimulation in nonfailing and failing human ventricular myocardium. Mol. Pharmacol. 35:295-303.

30. Buxton, I. L. O., and L. L. Brunton. 1983. Compartments of cyclic AMP and protein kinase in mammalian cardiomyocytes. J. Biol. Chem. 258:1023310239 . 